\title{
Partisan differences in Swedish macroeconomic policy
}

\author{
Mattias Erlandsson* \\ Department of Economics, Göteborg University
}

This version: June 7, 2001

\begin{abstract}
The purpose of this paper is to trace partisan differences among Swedish governments during the period 1958-1998. According to the Partisan Theory of macroeconomic policy left-wing governments are relatively more concerned with the performance of the real side of the economy (real output and unemployment) as compared to rightwing governments, that place a higher weight on the nominal variables (inflation). Left-wing governments would therefore pursue more expansionary aggregate demand policy, and thereby be willing to risk a higher inflation, in order to improve real economic performance. In this paper we apply the model developed in Hibbs (1994) on Swedish data. Our empirical results support the partisan theory, showing that, ceteris paribus, aggregate demand policy under left-wing governments is relatively more expansionary than under right-wing governments, even if the expansionary policy sometimes leads to higher inflation.
\end{abstract}

Keywords: Political economics, partisanship, macroeconomic policy

JEL code: D72, E60

\footnotetext{
${ }^{*}$ Correspondence Mattias Erlandsson, Department of Economics, Göteborg University, Box 640, SE-405 30 Göteborg, Sweden, email <mattias.erlandsson@economics.gu.se>. I am greatful for helpful comments from Douglas Hibbs. Generously financial support has been granted by Jan Wallander and Tom Hedelius' Stiftelse.
} 


\section{Introduction}

A whole new field of economics opened up once Nordhaus (1975) wrote "The political business cycle". The central assumptions of the Nordhaus model is that voters are myopic and that party policies are not determined by partisan differences. Rather, a governing party capitalizes on voters' myopia and runs the economic policy in a way that will maximize the probability of being re-elected. Consequently as an election nears the economy should be characterized by increasing growth and falling inflation, while having the opposite effect in periods immediately following the election. Therefore, the pure existence of elections generate economic fluctuations. In opposition to this view, Hibbs (1977) presents a model in which parties also behave "ideologically". Winning elections is important, but only to the degree that it enables the party to "implement policies favoring their core constituencies" (Hibbs [1992], p.34). This contrasting theory is called the Partisan Theory.

The foundations of the Partisan Theory (PT) of macroeconomic policy lies in the stylized fact that parties are made up of different core constituencies. The differences in preferences among these constituencies are based heavily on distributional consequences of changes in inflation and unemployment. Generally, one might say that supporters of left-wing parties are less endowed with financial capital. Therefore they rely heavily on labor income. This makes the income of left-wing voters uncertain in periods of high unemployment. Right-wing voters on the other hand often possess financial capital, which makes them primarily interested in keeping the inflation down. Consequently, the left-wing party is, at least marginally, more interested in high growth (leading to high employment) while the right-wing party focuses primarily on keeping the inflation rate down. In the early models of political business cycles it was assumed that the economy worked along an almost stable Phillips curve in the inflation-unemployment space, and that politicians could pick a point along the curve that was consistent with the preferences of their core constituencies.

The Rational Partisan Theory (RPT) was developed by Chappell and Keetch $(1986,1988)$ and by Alesina and Sachs (1988) as a revision of the original PT to fit into the neoclassical framework of rational expectations (RE). The original PT model was based on adaptive expectations, which allowed a backward sloping long-run Phillips curve (LRPC). In the RE paradigm, the LRPC is vertical. All attempts to increase aggregate demand 
by increasing government spending result in increased inflation. Alesina and Chappell and Keech tested the RPT by applying ideas of long-term wage contracts. They found that in a model with fixed and known party objectives, the presence of long-term unindexed nominal wage contracts with the contract period crossing an election, partisan influence on inflation and unemployment is possible due to uncertainty of the outcome of the election.

The empirical evidence that partisan effects exist on growth (and unemployment) and inflation is quite unanimous. Generally, partisan models outperform Nordhaus' political business cycle as an explanation for observed pattern of growth and inflation over administration periods. Tests of the traditional partisan theory, performed by Hibbs (1977) using U.S. post-war data on unemployment rates and Hibbs (1987) on growth, unemployment, fiscal and monetary policy show strong support for the partisan theory. Alesina and Roubini (1997) present calculations indicating that average real GDP growth during Democrat administrations from 1949-1994 was 4.2\%. The same measure during Republican presidencies was $2.4 \%$. The average inflation rate during the same period was $3.8 \%$ and $4.2 \%$ for Democrats and Republicans, respectively.

The big debate, though, is whether these observed partisan effects are transitory or permanent - that is, if the RPT is superior to the original PT. Alesina has, in different writings and with several co-authors, argued in favor of the RPT. For example, Alesina and Roubini (1992) test the RPT by regressing real output growth and the inflation rate, respectively, on lags of the dependent variable and a political variable accounting for the temporary partisan effect. This political variable is most often constructed as a dummy taking +1 or -1 and it is then lagged $\mathrm{N}$ quarters $(\mathrm{N}=4,6$ or 8$)$, where $\mathrm{N}=0$ represents the change of government. The aim of this exercise is to show that most partisan effects can be observed in the first half of an administration period. Alesina and Roubini (1992) find significant partisan effects in all their tests. The problem with the tests is, however, that they are not tests of RPT, since they do not test the very core of RPT - the uncertainty associated with the outcome of the election.

To test the core hypothesis of RPT, it is necessary to account for the degree of uncertainty in the election outcome. Alesina and Roubini (1997) 
convert pre-electoral polls into probabilities regarding the election outcome ${ }^{1}$. The uncertainty is then measured as a surprise, calculated as true voting outcome minus the probability of this outcome occurring. By including this in their regressions, Alesina and Roubini find that the surprise variable has a significant effect on post-electoral growth and unemployment, with the expected signs. (A surprising left-wing election victory results in increased growth and lower unemployment.) Furthermore, the greater the surprise, the larger the effect on the policy variable. The other central feature of the RPT is the existence of nominal inertia in wages. Carlsen (1998) utilizes a model first developed in Hibbs et al (1996), in which probability series of voting outcomes are generated and combined with data regarding the duration and density of wage contracts in the US. Contrary to the findings of Alesina and Roubini these studies find no evidence supporting the RPT. On the contrary, the observed partisan pattern in the data can be explained by a simple partisan dummy taking the values $+1 /-1$ for left- and right-wing governments. The amplitude of partisan differences in these studies is not affected by the degree of surprise in the election outcome.

The observed pattern of nominal spending and real output growth throughout the administration period is partisan divergence in the first half followed by convergence during the second half. Hibbs' (1994) explanation for this was that for politicians are uncertain about the sustainable output growth path. Based on realized economic outcomes, politicians ex post continually upgrade their goals. Using data from the US, Hibbs' paper gives empirical evidence that this ex post learning extended PT can explain much of the observed pattern over the election periods. The Hibbs (1994) model thus contrasts the RPT explanation, where the observed paths were due to the uncertainty in the election outcome.

One way to test for partisan effects in Sweden would be to use the same methodology as Hibbs et al. (1996). A fundamental assumption of this methodology is that wage contracts cross an election. In Sweden, however, the contract landscape has been dominated by synchronized contracts which typically have been renegotiated every year or every second year ${ }^{2}$. Fregert

\footnotetext{
${ }^{1}$ Alesina and Roubini build on a technique developed by Cohen (1993), in which he attempts to quantify the degree of surprise in an election outcome by taking ideas from option pricing theory and applying them to poll data.

${ }^{2}$ A potentially more important factor in determining the nominal inertia in an economy
} 
(1994) has summarized the Swedish wage negotiations from 1974 and on and by looking at these negotiations one can conclude that wage contracts in Sweden typically do not cross an election. In general, contracts have been renegotiated early in the calendar year following an election. Since elections in Sweden are held in September, it is reasonable to assume that the political consequences of a possible change in government will not show up before the turn of the calendar year. Despite this general feature of the wage contract structure, Carlsen and Pedersen (1999) include Sweden in their sample of countries when testing the RPT. They find partisan effects in Sweden, but they are not contingent on election surprises. Ohlsson and Vredin (1996) also find partisan differences when they examine Swedish fiscal policy from 19701993. Revenues are generally higher under left-wing governments compared to right-wing governments. The same is true for expenditures, although to a lesser extent.

In this paper we will test for partisan differences in Swedish macroeconomic policy using a methodology developed by Hibbs (1994). It is organized as follows: Section 2 presents some stylized facts on how the important economic variables in Sweden have evolved during left- and right-wing governments, respectively. In Section 3, we present the theoretical models underlying the empirical results presented in Section 4. Section 5 presents a numerical illustration of the main results. The paper ends with the concluding Section 6.

\section{A preliminary look at the data}

From 1958 to 1998 the dominating features of Sweden's economy were: (i) a consistently low unemployment rate up until the early 1990's, when a change in the monetary policy regime led to a rapid increase in the unemployment rate and (ii) an opposite general pattern for the inflation rate, which was high during most of the period up until the early 1990's and then fell substantially. This is illustrated in Figure 2.1. Swedish inflation history is similar to that of most Western countries. The two oil crises in the mid and late 1970's led to dramatic increases in the inflation rate. These adverse supply shocks,

is the existence of price rigidities. To quantify price rigidities and to map a potentially staggered stucture in prices is, however, not feasible. 
however, did not have any dramatic effect on Swedish unemployment which was consistently below $3.5 \%$ up until the early 1990's. The shift from left to right-wing governance in 1991 had large consequences for the Swedish economy. Not only did it imply a new government, it meant a change from the full-employment regime that had dominated the macroeconomic policy during the post-war period to a low-inflation regime. The pattern of real GDP growth follows the development of unemployment, although the effects on output from the change in monetary regime were less persistent than the unemployment effects.

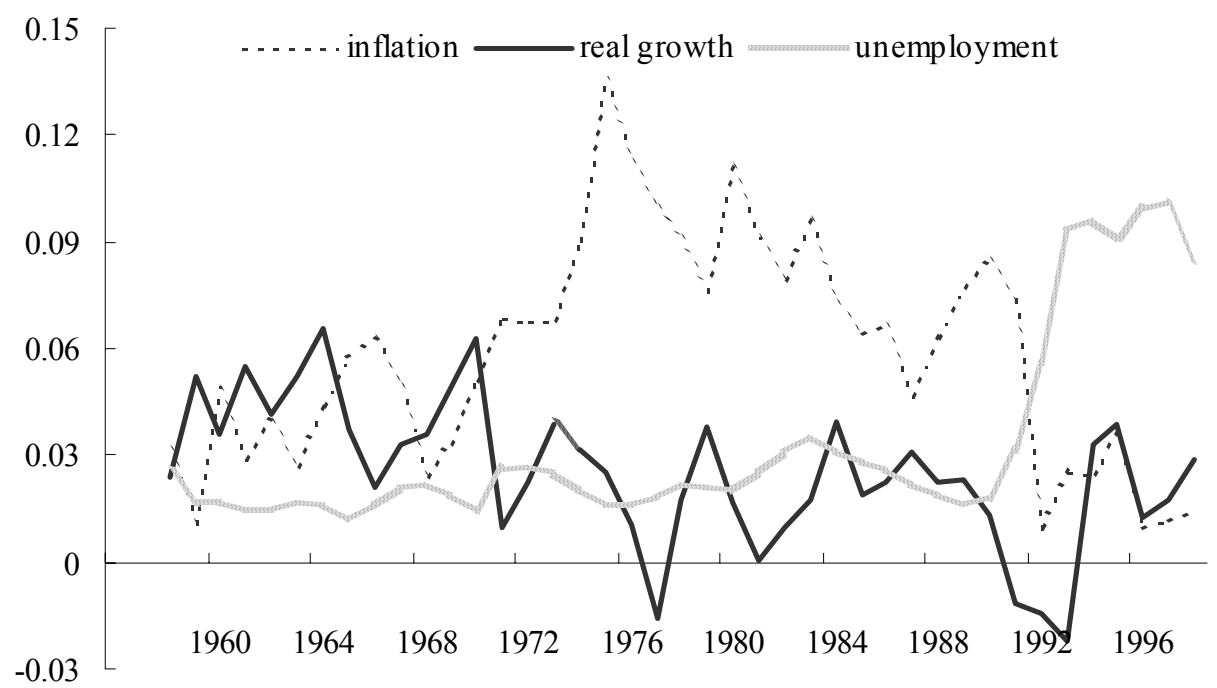

Figure 1. Inflation, real growth and unemployment in Sweden from 1958-1998

The data I will use for my empirical analysis in Section 4 cover the years 1958-1998. During this period Sweden had three periods of right-wing administration $^{3}$ and ten periods of left-wing governance. Figure 1 shows the development of inflation, real growth and unemployment in Sweden between 1958-1998. In Table 2.1 the same variables are averaged using the first, second

\footnotetext{
${ }^{3}$ The right-wing parties held office from 1976-1982 and 1991-1994.
} 
and third years of an administration period. ${ }^{4}$ Keeping in mind the potential problem with bias towards left-wing governments, the data gives clear indications of partisan patterns. Unemployment, on average, falls slightly for each year of left-wing administration, while it, on average, increases by more than one percent during the first year of right-wing governance. Right-wing governments generally inherit a high rate of inflation, but they manage to bring it down over the administration period. Some of this effect is due to the change in the monetary policy regime that took place in 1993 when inflation targeting was imposed as the objective for monetary policy, but the overall pattern is similar also when the election periods after 1993 are excluded.

Table 2.1 Some macroeconomic stylized facts by first to third year of left- and right-wing administrations, 1958-1998

\begin{tabular}{|c|c|c|c|}
\hline Year & Real GDP growth & Inflation & Unemployment \\
\hline & \multicolumn{3}{|c|}{ LEFT-WING ADMINISTRATION } \\
\hline First & 3.29 & 5.55 & 3.96 \\
\hline Second & 3.45 & 5.84 & 3.90 \\
\hline Third & 2.37 & 6.00 & 3.78 \\
\hline \multirow{2}{*}{$\begin{array}{l}\text { Cumulative } \\
\text { change }\end{array}$} & 9.11 & 17.39 & \\
\hline & \multicolumn{3}{|c|}{ RIGHT-WING ADMINISTRATION } \\
\hline First & -0.46 & 7.36 & 3.13 \\
\hline Second & -0.16 & 6.93 & 4.67 \\
\hline Third & 2.67 & 6.01 & 4.93 \\
\hline $\begin{array}{l}\text { Cumulative } \\
\text { change }\end{array}$ & 2.05 & 20.31 & \\
\hline
\end{tabular}

The accumulated growth over the period of administration is considerably higher under left- compared to right-wing administrations. This preliminary glance at the data suggests that partisan differences in Sweden do exist, but it is less clear whether these differences concern the potential tradeoff between inflation and unemployment or the trade-off between inflation and real growth. In the remainder of this paper we will therefore put both alternatives to the test.

\footnotetext{
${ }^{4} \mathrm{Up}$ until 1970 the term of office was four years. Therefore, from 1958-1970 only the first three years of an administration period have been used in Table 2.1.
} 


\section{The model}

\subsection{Intuition}

The main target variable for economic policy in Sweden has, at least up to 1992, been unemployment. This is true for left-wing as well as for rightwing governments. Keeping unemployment down, however, is not a "free lunch". One measure of the cost of keeping unemployment down is in terms of inflation. The hypothesis I want to test in this paper is whether it is possible to find partisan differences in Sweden in terms of this cost; specifically whether left-wing governments are more willing than right-wing governments to accept higher inflation as a "price" in order to bring down unemployment.

Early models describing political business cycles assume that preferences of political parties are stable over time and hence, not contingent on economic outcomes. The model in this paper is very similar to the work originally presented in Hibbs (1994). The key feature of the model is that politicians are uncertain about the sustainable path for the growth of real output (potential output) and about the natural rate of unemployment. Therefore, they are uncertain about how an expansionary policy will be divided between the real (output and unemployment) and the nominal (inflation) side of the macroeconomy. Contingent on continuous updating of the expected economic outcomes, in particular on the effects of an expansionary economic policy, the model allows politicians to revise their objectives in every time period. I implement this idea by assuming that governments use time-varying parameter estimates based on 30 years rolling regressions. ${ }^{5}$

\subsection{The Macroeconomy}

A structural equation for real output in the economy is assumed to be of the Lucas-form ${ }^{6}$. The trend-reverting log of real output $(q)$ is driven by (politically induced) expansions in aggreregate demand $(\Delta y)$ and shocks. We have

$$
q_{t}=\alpha(t)+\beta(t) T+\pi(t) \Delta y_{t}+\delta(t) q_{t-1}+\psi_{0}(t) z_{t}+\psi_{1}(t) z_{t-1}+\epsilon_{t}
$$

\footnotetext{
${ }^{5}$ Thirty years rolling regressions is an arbitrary choice, but the empirical results in the next section are not sensitive to the length of the rolling regressions.

${ }^{6}$ For a full derivation of this equation, see Lucas (1973).
} 
where $y$ denotes log nominal output, $\Delta$ is the first backward diffence and $T$ is a time trend. Supply shocks ${ }^{7}$ are captured by the variable $z$ and the demand shocks, $\epsilon$, are assumed to exhibit autoregressive persistence

$$
\epsilon_{t}=\phi_{i}(t) \epsilon_{t-i}+v_{t}, \quad i=1,2 \ldots
$$

The parameters in (1) and (2) are purposely written as time dependent, since the parameters are allowed to vary over time. The government is therefore uncertain about how a demand expansion will affect real output. It is assumed that the government generates guesses about correct parameter values by undertaking rolling regressions of equations (1) and (2). In Section 3.3 below the policy target will be defined. The government tries to attain this target by aggregate demand management. That is by setting $\Delta y_{t}$. However, since the policymakers do not know the realized value of $\pi(t)$, the government cannot, with certainty, predict how an increase in aggregate demand will affect real output. Inflation in the economy is given by the identity

$$
\Delta p_{t} \equiv \Delta y_{t}-\Delta q_{t}
$$

where $p_{t}$ is the log GDP deflator. Consequently, $\Delta p_{t}$, is the annual realized rate of inflation. The policymakers form their inflation expectations rationally by substituting (1) and (2), with best current estimates of the parameters $\left(\hat{\alpha}, \hat{\beta}, \hat{\pi}, \hat{\delta}, \hat{\psi}_{0}, \hat{\psi}_{1}\right.$ and $\left.\hat{\phi}_{i}\right)$ and the optimizing rate of demand expansion $\Delta y_{t}^{*}$, into (3). This gives us the following expression for the rationally expected inflation $\left(\Delta p_{t}^{e}\right)$

$$
\begin{aligned}
\Delta p_{t}^{e} & =\Delta y_{t}^{*}-\left(\hat{q}_{t}-q_{t-1}\right) \\
& =(1-\hat{\pi}(t)) \Delta y_{t}^{*}+(1-\hat{\delta}(t)) q_{t-1}-\left(\hat{\alpha}(t)+\hat{\beta}(t) T+\hat{\psi}_{1}(t) z_{t-1}+\epsilon_{t}\right)
\end{aligned}
$$

where a hat indicates that the parameter is estimated. In equation (4) the estimated time-varying parameters are defined as $\hat{x}(t)=E\left(x_{t} \mid I_{t-1}\right)$ where the vector $I_{t-1}$ includes information of realized economic variables up to period $t-1^{8}$. The supply shock in period $t$ is not included in the determination of expected inflation, since we assume that $E\left(z_{t} \mid I_{t-1}\right)=0$.

\footnotetext{
${ }^{7}$ In the empirical work ahead we use the proportional change in the real price of oil defined as $\left[\left(\ln \left(O I L_{t}\right)-\ln \left(O I L_{t-1}\right)\right)-\left(\ln \left(P_{t}\right)-\ln \left(P_{t-1}\right)\right)\right]$, where $O I L_{t}$ is the price of crude oil, in the domestic currency, and $P_{t}$ is the GDP deflator. This relative price change is weighted by the change in net oil imports over real GDP.

${ }^{8}$ That is, the expected value of the parameters for period $t$ are obtained by rolling regressions of equation (1) and (2) over the period $t-30$ to $t-1$.
} 
In Section 2 we saw that the party split in Swedish macroeconomic policy might just as well concern the trade-off between inflation and unemployment as the trade-off between inflation and real output. Using unemployment as the policy target variable is, however, trickier than using real output. There are several reasons for this: (i) data on unemployment are often less reliable, but the main difficulty is that (ii) the link from the policy instrument (i.e. increases in nominal spending) to unemployment may be either through increases in real output or through increased inflation (that is, if the Phillips curve is downward-sloping). Based on simple OLS estimations on Swedish data, we conclude that the most important determinant of unemployment is growth of real output. When the government forms its expectations of unemployment for the following period we therefore assume that it uses an Okun-like relationship

$$
\hat{U}_{t}=\hat{\alpha}_{u}(t)+\hat{\eta}(t)\left(\hat{q}_{t}-q_{t-1}\right)+\hat{\gamma}(t) U_{t-1}
$$

where $U_{t}$ is the unemployment rate (measured in percentage points). The government can then affect the unemployment rate through real output growth by aggregate demand management.

\subsection{Partisan objectives}

In the following empirical estimations we will use both real output as well as unemployment as policy target variables. The specifications of the targets are similar.

\subsubsection{Real output as the policy target variable}

In the rich literature on partisan theory the variable most commonly used to measure the real side of the economy is the growth of real output. I assume that the government log real output target, $q_{t}^{T}$, for each period can be written

$$
q_{t}^{T}=\hat{\alpha}(t)+\left\{\Pi_{\text {left }}(t) L_{t}+\Pi_{\text {right }}(t)\left(1-L_{t}\right)\right\} \hat{\beta}(t) T+\hat{\pi}(t) \Delta y_{t}^{*}+\hat{\delta}(t) q_{t-1}
$$

where $\Pi_{\text {left }}(t)$ and $\Pi_{\text {right }}(t)$ are the time-varying partisan target variables and $L_{t}$ is a binary variable equal to one during years of left-wing governance - zero otherwise. The time-varying partisan target variables are stated as multiples of the estimated trend growth rate of output, which allows the model to capture the fact that the output target of the party in office may vary depending on where in the business cycle the politicians anticipate the 
economy to be. These time-varying output targets are defined as

$$
\Pi_{j}(t)=\beta_{j}^{q}+\beta_{p 0}^{q} \Delta p_{t}^{e}+\Sigma_{i} \beta_{p i}^{q} \Delta p_{t-i-1}, \quad j=\text { left, right }
$$

where the expected inflation, $\Delta p_{t}^{e}$, is generated according to equation (4). The partisan target variables vary with the expected and realized rates of inflation, reflecting that in periods of high expected and/or realized inflation, the incumbent government may want to choose a lower target value for real output. All $\beta^{q}$ 's are parameters to be estimated in Section 4 , where $\beta_{\text {left }}^{q}$ and $\beta_{\text {right }}^{q}$ are the "deep" parameters, reflecting the different partisan preferences. We expect at least one of $\beta_{p 0}^{q}$ or the $\beta_{p i}^{q}$ 's to be negative and, assuming that parties do not differ in their formation of inflation expectations, if partisan theory applies to Sweden it must be the case that $\beta_{\text {left }}^{q}>\beta_{\text {right }}^{q}$.

The government chooses an optimizing rate of aggregate demand expansion by minimizing its expected loss function

$$
\begin{aligned}
E\left(\Lambda_{t}^{q}\right) & =E\left(q_{t}-q_{t}^{T}\right)^{2} \\
& =\sigma_{\hat{q}_{t}}^{2}+\left(\hat{q}_{t}-q_{t}^{T}\right)^{2}
\end{aligned}
$$

where $\sigma_{\hat{q}_{t}}^{2}$ is the one step ahead variance of forecast output. ${ }^{9}$ Minimizing (8) subject $(1),(2),(6)$ and $(7)$ gives that the optimal rate of aggregate demand expansion, $\Delta y_{t}^{*}$ can be written:

$$
\begin{array}{r}
\Delta y_{t}^{*}=\frac{\sigma_{\hat{\pi}}^{2}}{\Lambda(t)+\sigma_{\hat{\pi}}^{2}} \Delta \bar{y}(t)+\frac{\Lambda(t)}{\Lambda^{2}(t)+\sigma_{\hat{\pi}}^{2}}\left(q_{t}^{T}-\hat{q}_{t}\right) \\
-\frac{1}{\Lambda^{2}(t)+\sigma_{\hat{\pi}}^{2}}\left\{(T-\bar{T}) \sigma_{\hat{\pi}, \hat{\beta}}+\left(q_{t-1}-\bar{q}_{t-1}\right) \sigma_{\hat{\pi}, \hat{\delta}}+\right. \\
\left.\quad\left(z_{t-1}-\bar{z}_{t-1}\right) \sigma_{\hat{\pi}, \hat{\psi}}+\Sigma_{i}\left(\epsilon_{t-i}-\bar{\epsilon}_{t-i}\right) \sigma_{\hat{\pi}, \hat{\phi}_{i}}\right\}
\end{array}
$$

where $\Lambda(t)=\left[\beta_{p 0}^{q}(\hat{\pi}(t)-1) \hat{\beta}(t) T\right]$.

\footnotetext{
${ }^{9}$ The one-period ahead variance of expected real output, $\hat{q}_{t}$, is given by

$$
\sigma_{\hat{q}_{t}}^{2}=\sum_{m}\left(x_{m}-\bar{x}_{m}\right)^{2} \sigma_{\hat{\Omega}_{m}}^{2}+2 \sum_{m \neq n}\left(x_{n}-\bar{x}_{n}\right)\left(x_{m}-\bar{x}_{m}\right) \sigma_{\hat{\Omega}_{n}, \hat{\Omega}_{m}}
$$

where $x_{m}$ denotes the explanatory variables in (1) and (2), that is $T, \Delta y^{*}, q_{t-1}, z_{t-1}$ and $\varepsilon_{t-i}$. A bar, $\bar{x}_{m}$, indicates the mean of a variable. The vector $\hat{\Omega}_{m}$ contains the estimated parameters $\hat{\beta}, \hat{\pi}, \hat{\delta}, \hat{\psi}_{1}$ and $\hat{\phi}_{i}$. The term $\sigma_{\hat{\Omega}_{m}}^{2}$ denotes the sample variances and $\sigma_{\hat{\Omega}_{n}, \hat{\Omega}_{m}}$ the sample covariances of these parameters. Time indexes are supressed in the above equation, but since all parameters are time varying, a new parameter vector is estimated in each time period.
} 


\subsubsection{Unemployment as the policy target variable}

The next step is to formulate an unemployment policy target, which should be stated in terms of the estimated natural rate. Drazen (2000) makes the assumption that the two parties differ in their estimates of the natural rate of unemployment, with a tendency of the left-wing party to underestimate the natural rate and a tendency of the right-wing party to overestimate it. I will take a similar approach and assume that the parties do not differ in the way they estimate the natural rate of unemployment, but that the left-wing party is more willing accept the risk of higher inflation to see if a natural rate lower than the current autoregressive estimate (cf. footnote 13 in Section 4.2) might be sustained. I assume the unemployment target for period $t$ to be

$$
U_{t}^{T}=\hat{U}_{t}^{N A T}\left\{\Lambda_{\text {left }}(t) L_{t}+\Lambda_{\text {right }}(t)\left(1-L_{t}\right)\right\}
$$

where $\Lambda_{\text {left }}(t)$ and $\Lambda_{\text {right }}(t)$ are defined as in $(7)^{10}$ and now denotes the timevarying unemployment targets for the left-wing and right-wing parties, respectively. $\hat{U}_{t}^{N A T}$ denotes the estimated natural rate of unemployment. The expected loss function is expressed as a direct parallel to (8). For period $t$ the expeced loss is defined as

$$
\begin{aligned}
E\left(L_{t}^{U}\right) & =E\left(U_{t}-U_{t}^{T}\right)^{2} \\
& =\sigma_{\hat{U}_{t}}^{2}+\left(\hat{U}_{t}-U_{t}^{T}\right)^{2}
\end{aligned}
$$

where $\hat{U}_{t}$ is the expected unemployment rate in period $t$, based on rolling regressions of equation (5) and where $U_{t}^{T}$ is the unemployment target prevailing for period $t$. Figure 1 shows that the variance in Swedish unemployment has been quite low, why I assume all uncertainty terms to be zero. ${ }^{11}$ Proceeding like in Section 3.3.1 and minimizing this loss function with respect to nominal output expansion then gives us the optimality condition

$$
\Delta y_{t}^{*}=\frac{1}{\Theta(t)}\left[U_{t}^{T^{\prime}}-\hat{U}_{t}^{\prime}\right]
$$

where $\Theta(t)=\left[\hat{\pi}(t) \hat{\eta}(t)-\hat{U}_{t}^{N A T} \beta_{p 0}(1-\hat{\pi}(t))\right], \hat{U}_{t}^{\prime}=\left[\hat{U}_{t}-\hat{\pi}(t) \hat{\eta}(t) \Delta y_{t}^{*}\right]$ and $U_{t}^{T^{\prime}}=\left[U_{t}^{T}-\hat{U}_{t}^{N A T} \beta_{p 0}(1-\hat{\pi}(t)) \Delta y_{t}^{*}\right]$.

\footnotetext{
${ }^{10}$ The only difference is of course that the parameters may be different, that is $\Omega_{j}(t)=\beta_{j}^{u}+\beta_{p 0}^{u} \Delta p_{t}^{e}+\Sigma_{i} \beta_{p i}^{u} \Delta p_{t-i-1}, \quad j=$ left, right

${ }^{11}$ This assumption simplifies the expression for optimal aggregate expansion $\left(\Delta y_{t}^{*}\right)$ considerably.
} 


\section{Empirical results}

\subsection{Real output as the policy target variable}

The results from nonlinear least squares estimation of equation (9) are presented in table 4.1. A comparison between the estimated value of the two partisan parameters, $\beta_{\text {left }}^{q}$ and $\beta_{\text {right }}^{q}$ gives significant indications of partisan differences among policymakers in Sweden. If we do not account for the inflation effect, the interpretation of regression (1) in Table 4.1 below is that over a three-year administration period left-wing governments set real output growth targets $3.3 \%$ above the estimated historical trend growth of real output. The corresponding value for right-wing governments is $0.6 \%$ below estimated trend growth. Even if the annual diffence is quite small $\left(\beta_{\text {left }}^{q}-\beta_{\text {right }}^{q}=0.013\right)$, low standard errors enable us to state that the diffence is statistically significant. If the estimation is undertaken with all uncertainty terms equal to zero, as in regressions (3) and (4), the partisan difference increases slightly. The interpretation is that uncertainty about how an aggregate demand expansion will actually be divided between inflation and real output growth makes the Swedish policymakers less prone to undertake an expansionary policy and to be less partisan.

The regressions (1) and (2) are similar, but differ in how many previous inflation records governments account for when forming their time-varying policy targets for the coming period. Successive inclusion of inflation in period $t-2$ shows that expected inflation has a substantial negative influence on the formation of growth targets. Realized inflation two periods ago does not appear to have a significant impact on the formation of output targets in the current period. Using regression (1) we can write a linear combination of the inflation parameters $-0.98 \Delta p_{t}^{e}+0.36 \Delta p_{t-1}$. Hence, Swedish governments partly accommodate the previous year's inflation, while the expected inflation for the current year is resisted. With the right-wing governments in office during the high inflation second half of the 70's, the evidence indicates that right-wing governments typically pursued output growth targets well below the historical trend ${ }^{12}$.

\footnotetext{
${ }^{12}$ In Appendix, the estimated time-varying partisan parameters, $\Pi_{j}$ from equation (7), are presented for every year from 1960-1998.
} 
Table 4.1 Estimates for aggregate demand expansion $\left(\Delta y_{t}\right)$ models, policy target variable; log of real GNP, $q_{t}$, annual data 1958-1998

\begin{tabular}{|c|c|c|c|c|}
\hline \multirow[b]{2}{*}{ Coefficient } & \multicolumn{4}{|c|}{ Regression models } \\
\hline & $(1)^{a}$ & $(2)^{a}$ & $(3)^{b}$ & $(4)^{b}$ \\
\hline \multirow[t]{2}{*}{ constant } & -0.013 & -0.01 & -0.013 & -0.010 \\
\hline & $(-0.70)$ & $(-0.44)$ & $(-0.70)$ & $(-0.51)$ \\
\hline \multirow{2}{*}{$\beta_{\text {left }}^{q}$} & 1.011 & 1.008 & 1.032 & 1.029 \\
\hline & $(73.0)$ & $(67.7)$ & $(96.2)$ & $(87.6)$ \\
\hline \multirow[t]{2}{*}{$\beta_{\text {right }}^{q}$} & 0.998 & 0.994 & 1.015 & 1.010 \\
\hline & $(66.7)$ & $(58.1)$ & $(83.5)$ & $(71.4)$ \\
\hline \multirow[t]{2}{*}{$\beta_{p 0}^{q}$} & -0.985 & -0.980 & -0.995 & -0.991 \\
\hline & $(-8.51)$ & $(-8.45)$ & $(-8.41)$ & $(-8.68)$ \\
\hline \multirow[t]{2}{*}{$\beta_{p 1}^{q}$} & 0.364 & 0.307 & 0.360 & 0.300 \\
\hline & $(3.45)$ & $(2.13)$ & $(3.52)$ & $(2.12)$ \\
\hline \multirow[t]{2}{*}{$\beta_{p 2}^{q}$} & & 0.077 & & 0.087 \\
\hline & & $(0.54)$ & & $(0.65)$ \\
\hline Adjusted $\bar{R}^{2}$ & 0.39 & 0.37 & 0.30 & 0.28 \\
\hline Durbin-Watson & 1.63 & 1.57 & 1.42 & 1.34 \\
\hline Significance level for $\beta_{\text {left }}=\beta_{\text {right }}$ & 0.033 & 0.034 & 0.007 & 0.007 \\
\hline
\end{tabular}

${ }^{a}$ Estimations based on equation (9) in the text.

${ }^{b}$ Estimations with the uncertainty terms set to zero

$t$-statistics in parentheses.

Hence, as implied by the stylized facts in Section 2 and in accordance with the partisan theory, the evidence indicates that left-wing governments in Sweden pursue less disinflationary growth-oriented aggregate demand policies than right-wing governments. The regression results also imply that higher expected inflation leads politicians to lower their real output targets. The effect of expected inflation seems to be a greater determinant than the inherited inflation.

\subsection{Unemployment as the policy target variable}

A problem with using unemployment as the policy target variable is the choosing an instrument for the natural rate of unemployment. One suggestion would be to use time-varying estimates of the Non Accelerating Inflation 
Rate of Unemployment (NAIRU). In this section we will not use the NAIRU, but instead focus on the fact that unemployment has proven to be highly persistent. Consequently, the most important determinants of unemployment in period $t$ are the realized unemployment rates in the most recent periods, $t-i .{ }^{13}$ Using these estimates as instruments for the natural rate I then estimate equation (12).

Table 4.2 Estimates for aggregate demand expansion models $\left(\Delta y_{t}\right)$, policy target variable; the unemployment rate $u_{t}$, annual data 1958-1998

\begin{tabular}{|c|c|c|}
\hline \multirow[b]{2}{*}{ Coefficient } & \multicolumn{2}{|c|}{ Regression models } \\
\hline & $(5)$ & (6) \\
\hline \multirow[t]{2}{*}{ constant } & -0.004 & -0.004 \\
\hline & $(-0.19)$ & $(-0.19)$ \\
\hline \multirow[t]{2}{*}{$\beta_{l e f t}^{u}$} & 0.980 & 0.979 \\
\hline & $(8.60)$ & $(8.37)$ \\
\hline \multirow{2}{*}{$\beta_{\text {right }}^{u}$} & 1.025 & 1.021 \\
\hline & $(9.57)$ & $(8.89)$ \\
\hline \multirow[t]{2}{*}{$\beta_{p 0}$} & 6.237 & 6.240 \\
\hline & $(6.92)$ & $(2.99)$ \\
\hline \multirow{2}{*}{$\beta_{p 1}$} & -5.252 & -5.340 \\
\hline & $(-6.27)$ & $(-2.82)$ \\
\hline \multirow[t]{2}{*}{$\beta_{p 2}$} & & 0.127 \\
\hline & & $(0.11)$ \\
\hline$\overline{R^{2}}$ & 0.51 & 0.49 \\
\hline Durbin-Watson & 2.06 & 2.06 \\
\hline Significance level for $\beta_{\text {left }}=\beta_{\text {right }}$ & 0.370 & 0.441 \\
\hline
\end{tabular}

The estimations, using unemployment as the policy target variable, give indications of partisan effects in Swedish macroeconomic policymaking, although the estimated difference is less significant than the results I achieved with real output as the target variable. In both regressions the partisan parameter are smaller for left- than for right-oriented governments $\left(\beta_{\text {left }}^{u}<\beta_{\text {right }}^{u}\right)$.

\footnotetext{
${ }^{13}$ More specifically I recursively estimate the equation $u_{t}=\alpha_{u}(t)+\Sigma_{i} \theta_{t-i}(t) u_{t-i}$ for $i=1$ to 8 .
} 
The interpretation is that left-wing governments choose a lower unemployment target than right-wing governments. There is no case, however, where the partisan difference is statistically significant. Once again the estimations imply that expected inflation has a significant influence on the optimal choice of aggregate demand expansion, as does the inherited inflation from the previous period. An expected acceleration in inflation from period $t-1$ to period $t$ increases the unemployment target and in periods of high inflation, the government's unemployment target lies above the estimated natural rate of unemployment. Realized inflation two periods earlier does not seem to have any influence on the unemployment policy target.

\section{Numerical illustration}

The validity of the results presented in this paper is tested by a static simulation of the model. The result from regression (3) is used in Figure 2. That is, the simulated equation for optimal expansion of nominal spending is

$$
\Delta y^{*}=\frac{1}{\Lambda(t)}\left(q_{t}^{T}-\hat{q}_{t}\right)
$$

with $q_{t}^{T}$ and $\hat{q}_{t}$ defined as in equations (6) and (1) - (2).

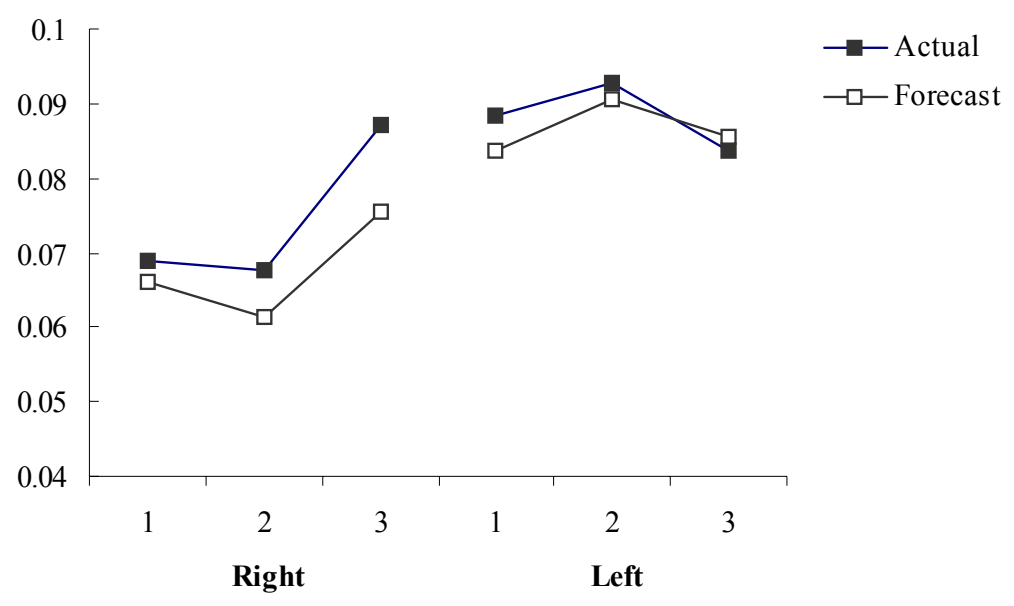

Figure 2. Growth rate of nominal spending $(\Delta y)$

The model is effective at predicting the partisan pattern in nominal spending, characterized by partisan divergence during the first two years of a gov- 
ernment's tenure and convergence the third year (the election year). When the left-wing party wins an election it increases aggregate demand the first and second years in order to increase real growth and employment. This creates an inflationary pressure in the economy. The rise in inflation leads left-wing politicians to revise their target for real output (by equation (6)) which thus leads to a decreased rate of demand expansion $(\Delta y)$ by the third year of governance. The opposite pattern is typical when a right-wing party wins an election. The rate of increase in nominal spending is lowered to bring down inflation. As inflation is reduced, the right-wing policymaker shifts focus to increase real growth. Again, the specification of the timevarying output target allows the third year of an administration period to exhibit the partisan convergence that corresponds to actual data. Figures (3) and (4) below show the predicted division of an aggregate demand expansion into real growth and inflation. ${ }^{14}$

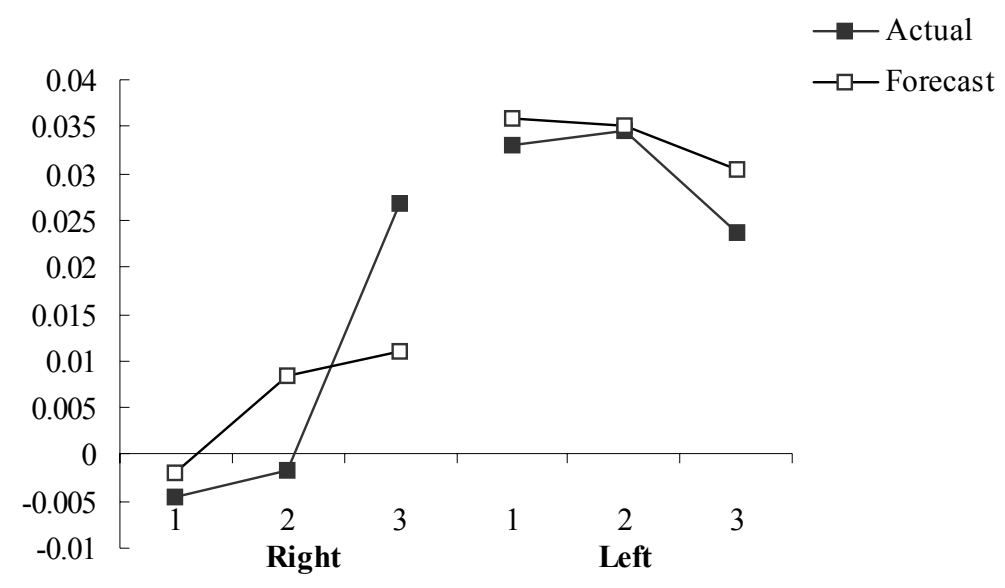

Figure 3. Growth rate of real output $(\Delta q)$

The model is less effective at predicting the convergence in real growth rates the third year of a government's tenure. Since forecasted inflation is

${ }^{14}$ These predictions are calculated using the identities

$$
\Delta \hat{q}_{t} \equiv \hat{q}_{t}-q_{t-1} \quad \text { and } \quad \Delta \hat{p}_{t} \equiv \Delta y_{t}^{*}-\Delta \hat{q}_{t}
$$


calculated residually, the underestimation of the third year's real growth for a right-wing government results in an overestimation of inflation the third year. The opposite pattern is true for left-wing governmnents.

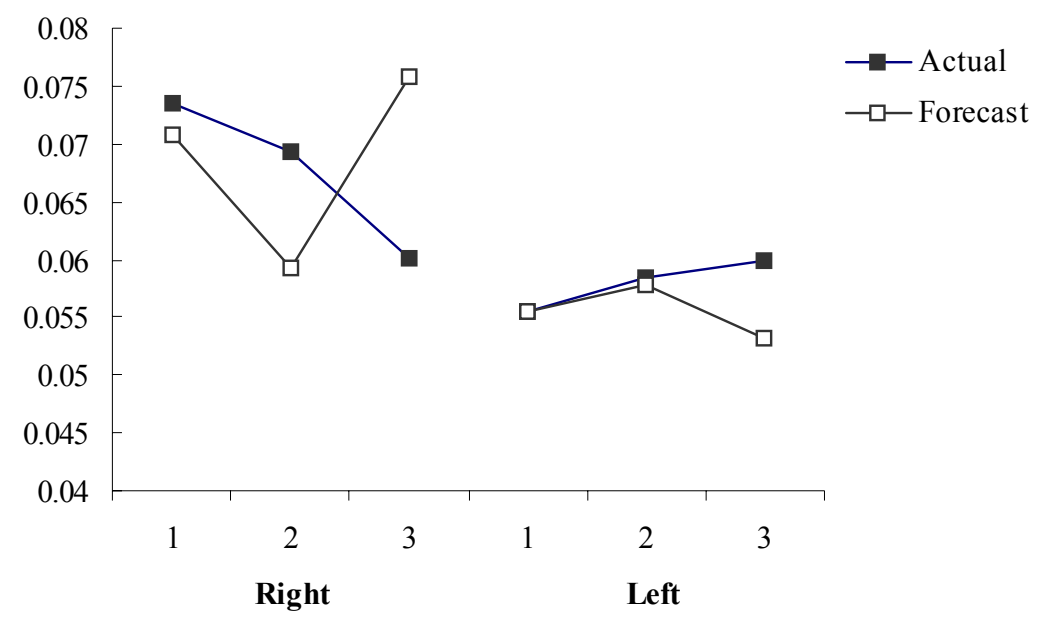

Figure 4. Growth rate of the GNP deflator $(\Delta p)$

\section{Conclusions}

The purpose of this paper is to use the model first presented in Hibbs (1994) to trace partisan differences in Swedish macroeconomic policy using data for the time period 1958-1998. Statistically significant partisan differences are found when real output is used as the policy target variable. The results show that left-wing governments in Sweden generally pursue an economic policy aimed at pushing real output growth above the estimated historical trend. Both realized previous inflation and expected current inflation have dampening effect on the government's choice of aggregate demand expansion. When accounting for this inflation effect, right-wing governments typically aim for a demand expansion below the historical trend. I have not been able to establish significant partisan effects with unemployment as the policy target variable, although the results in Table 4.2 give indications of partisan differences. The results in this paper are consistent with previous research using Swedish data. 


\section{Appendix}

\subsection{The time-varying partisan parameters.}

The estimates of $\Pi_{\text {left }}(t)$ and $\Pi_{\text {right }}(t)$ based on regression (3) in Table 4.1 are shown in Table A1:

Table A.1 Estimates the partisan parameters, $\Pi_{i}(t)$

\begin{tabular}{cccccc}
\hline \multicolumn{5}{c}{ Variable } & \multicolumn{3}{c}{ Variable } \\
year & $\Pi_{\text {left }}(t)$ & $\Pi_{\text {right }}(t)$ & year & $\Pi_{\text {left }}(t)$ & $\Pi_{\text {right }}(t)$ \\
\hline 1960 & 1.022 & - & 1980 & - & 0.981 \\
1961 & 0.989 & - & 1981 & - & 0.996 \\
1962 & 1.007 & - & 1982 & - & 0.992 \\
1963 & 1.002 & - & 1983 & 0.995 & - \\
1964 & 1.008 & - & 1984 & 0.968 & - \\
1965 & 1.020 & - & 1985 & 0.988 & - \\
1966 & 1.010 & - & 1986 & 0.991 & - \\
1967 & 0.997 & - & 1987 & 1.037 & - \\
1968 & 0.999 & - & 1988 & 0.987 & - \\
1969 & 0.998 & - & 1989 & 1.024 & - \\
1970 & 0.993 & - & 1990 & 0.991 & - \\
1971 & 1.014 & - & 1991 & 0.996 & - \\
1972 & 0.990 & - & 1992 & - & 0.995 \\
1973 & 1.007 & - & 1993 & - & 1.020 \\
1974 & 1.005 & - & 1994 & - & 0.980 \\
1975 & 0.977 & - & 1995 & 1.008 & - \\
1976 & 1.021 & - & 1996 & 1.004 & - \\
1977 & - & 1.005 & 1997 & 1.011 & - \\
1978 & - & 0.997 & 1998 & 1.008 & - \\
1979 & - & 0.989 & & & \\
\hline$N 0 t e:$ & $C a l c 17$ & & &
\end{tabular}

Note: Calculations are based on the results presented in regression (3) in Table 4.1 


\section{References}

Alesina, A. and N. Roubini (1992), "Political Cycles in OECD Countries" Review of Economic Studies 59: 663-688

Alesina, A. , N. Roubini and G. D. Cohen (1997), Political Cycles and the Macroeconomy, MIT Press, Cambridge, Massachusetts

Alesina, A. and J. Sachs (1988), "Political Parties and the Business Cycle in the US" Journal of Money, Credit and Banking 20: 63-82

Carlsen, F. (1998), "Rational Partisan Theory: Empirical Evidence for the United States" Southern Economic Journal 65: 64-82

Carlsen, F. and E. F. Pedersen (1999), "Rational Partisan Theory: Evidence for Seven OECD Economies" Economics and Politics 11: 13-32

Chappell, H.W. and W. R. Keech (1986), "Party Differences in Macroeconomic Policies" American Economic Review 76: 71-74

Chappell, H.W. and W. R. Keech (1988), "The Unemployment Consequence of Partisan Monetary Regimes" Southern Economic Journal 55: 107122

Cohen, G. (1993), Pre- and Post-Electoral Macroeconomic Fluctuations Dissertation, Department of Economics, Harvard University.

Drazen, A. (2000), Political Economy in Macroeconomics, Princeton University Press, Princeton, New Jersey.

Fregert, K. (1994), Wage contracts, policy regimes and business cycles: a contractual history of Sweden 1908-1990, Lund Economic Studies 54, Lund, Sweden

Hibbs, D. A. (1977), "Political Parties and Macroeconomic Policy" American Political Science Review 7: 1467-87

Hibbs, D. A. (1987), The American Political Economy: Macroeconomics and Electoral Politics in the United States. Harvard University Press, Cambridge, MA. 
Hibbs, D. A. (1992), "Partisan Theory after Fifteen Years" European Journal of Political Economy 8: 361-373

Hibbs, D. A. (1994), "The Partisan Model of Macroeconomic Cycles: More Theory and Evidence from the United States" Economics and Politics 6: $1-23$

Hibbs, D. A., Carlsen, F. and Pedersen (1996), "Electoral Uncertainty and Partisan Output Cycles" Working Paper, Department of Economics, Norwegian University of Science and Technology, Trondheim, Norway

Lucas, R. E. (1973), "Some International Evidence on Output-Inflation Tradeoffs" American Economic Review 63: 326-334

Nordhaus, W. (1975), "The Political Business Cycle" Review of Economic Studies 42: 169-190

Ohlsson, H. and A. Vredin (1996), "Political Cycles and Cyclical Policies" Scandinavian Journal of Economics 98: 203-218 